\title{
Practices surrounding syringe acquisition and disposal: effects of Syringe Exchange Programmes from different Brazilian regions- the AjUDE-Brasil II Project
}

\author{
Waleska Teixeira Caiaffa ${ }^{\mathrm{a}, *}$, Francisco Inácio Bastos ${ }^{\mathrm{b}}$, Fernando Augusto Proietti ${ }^{\mathrm{a}}$, \\ Ângela Cristina Maia Reis ${ }^{c}$, Sueli Aparecida Mingoti ${ }^{c}$, Denise Gandolfi ${ }^{d}$, \\ Denise Doneda ${ }^{\mathrm{d}}$, DeniseDoneda ${ }^{\mathrm{d}}$ AjUDE-Brasil II Project \\ a Department of Preventive and Social Medicine of Federal University of Minas Gerais State (UFMG) and Research \\ Group in Epidemiology (GPE/UFMG), Av. Alfredo Balena 190, 10o. andar, 30130-100 Belo Horizonte, Minas Gerais, Brazil \\ b Oswaldo Cruz Foundation, Rio de Janeiro, Brazil \\ ${ }^{\mathrm{c}}$ Department of Statistics of UFMG, Belo Horizonte, Minas Gerais, Brazil \\ d National STD/AIDS Program, Ministry of Health, Brazil
}

Received 1 December 2002; received in revised form 15 March 2003; accepted 2 July 2003

\begin{abstract}
The study describes practices relating to syringe acquisition and disposal by Syringe Exchange Programme (SEP) participants. A crosssectional multi-city study enrolled 857 injection drug users (IDUs) from six SEPs in different Brazilian regions, and assessed self-reported acquisition and disposal behaviours. Seven hundred and nine males (82.9\%) and 146 females (17.1\%) were recruited through outreach and interviewed, most from the streets or their neighbourhoods $(54.1 \%)$. The average age was 28.5 years; $76.4 \%$ reported injecting cocaine in the past 6 months. Sources for acquiring new syringes differed significantly between time of injection drug use debut and the 6 months prior to interview. Fifty-three percent of IDUs reported acquiring their syringes in pharmacies when they initiated injection drug use, whereas most reported acquiring new syringes in the 6 months before interview from several simultaneous sources: $69 \%$ through SEPs; 58\% through pharmacies; $36 \%$ from friends and/or sexual partners; and 17\% from other health services. Across SEPs, acquisition and disposal varied widely. Most interviewees discarded their syringes on the streets, in open fields, or in the garbage or sewage. Restrictions on syringe availability and unsafe practices may be functioning as barriers to the public health recommendation of one-time use of sterile syringes for IDUs and discouraging community support to SEPs. Further increase in access to legal, inexpensive and timely sterile syringes, as well as counselling about the merits of one-time use and safer disposal must be reinforced as part of efforts to minimise high-risk behaviours and curb the spread of blood-borne infections.
\end{abstract}

(C) 2003 Elsevier B.V. All rights reserved.

Keywords: IDUs; Syringes; Needles; HIV/AIDS

\section{Introduction}

Brazil is a country of 175 million inhabitants, heterogeneously distributed across its large territory, and with deep geographic, social and cultural contrasts between regions. The epidemiology of Human Immunodeficiency Virus (HIV) in Brazil is also heterogeneous, varying widely between geographic regions and subpopulations affected.

\footnotetext{
* Corresponding author.

E-mail address: wcaiaffa@medicina.ufmg.br (W.T. Caiaffa).
}

Injection drug users (IDUs) have had a key role in the epidemiology of HIV in some regions of Brazil (the Southeast, the South, the southernmost part of the Northeast and part of the Centre-West). In the mid-1990s, IDUs constituted almost $30 \%$ of all AIDS cases, and of the 237,588 AIDS cases reported in Brazil as of March 2002, about 20\% were IDUs (Brazil, 2002). While in the Southeast region HIV incidence seems to be reaching a plateau, incidence rates in the South are still increasing, mainly due to IDU-related transmission, provoking a persistent shift in the dynamics of the national epidemic. In some municipalities located in the southern part of the country, IDUs constitute over $50 \%$ 
of all reported AIDS cases (Brazil, 2002; Caiaffa, Proietti, Mingoti, et al., 2002).

The first Brazilian Syringe Exchange Programme (SEP) opened in Salvador, Bahia State, in 1994. From 1992 to 1996, the implementation of SEPs was erratic, facing strong opposition from local conservative forces. Since 1996, the number and operational capacity of SEPs has increased. Despite scarcity of funds and conflicts with conservative forces, harm prevention strategies have gained momentum in Brazil, growing into a comprehensive network of different programmes on a scale unparalleled in any other middleor low-income country (Bastos \& Strathdee, 2000).

To date, more than 100 SEPs are operative in different regions of Brazil, supported by a consortium of local organisations, the Brazilian Ministry of Health and international agencies. SEPs include established projects, pilot studies and exchange outlets affiliated with other health services. Aside from syringe exchange or distribution, ancillary services are available, such as condom distribution, risk reduction and voluntary counselling, and referrals to HIV testing and health treatment. However, by international standards, the SEPs operating in Brazil are still rather small-scale projects, exchanging around 15,000-20,000 syringes per month. Expansion has been limited by lack of managerial capacity, scarce resources and untrained staff (Bastos, 2000).

Access to sterile syringes is an important factor in reducing syringe reuse and sharing, and consequently the spread of blood-borne infections, such as HIV/AIDS, Hepatitis B and C (Diaz, Chu, Weinstein, et al., 1998; Heimer, Khoshmood, Bigg, et al., 1998; Lurie, Gorsky, Jones, \& Shomhe, 1998). However, increasing the safety of syringe disposal remains a challenge. Although some studies have shown that the risk of transmission of HIV or other blood-borne pathogens resulting from a needlestick injury from a syringe discarded in the community is negligible, viable HIV can be found in 10-40\% of disposed syringes (Chitwood, Clyde, Inciardi, et al., 1990; Macalino, Springer, Rahman, et al., 1998; Montella, Di Sora, \& Recchia, 1992). Unsafe syringe disposal also provokes strong negative responses in most communities.

Even those IDUs who are regular clients of SEPs seek complementary syringe sources and use alternative disposal strategies, partially influenced by prescription and paraphernalia laws, local drug policies and law enforcement practices, and informal drug and drug paraphernalia dynamics (Gleghorn, Gee, \& Vlahov, 1998; Groseclove, Weinstein, Jones, et al., 1995; Heimer et al., 1998; Lurie et al., 1998; Macalino et al., 1998).

Practices related to syringe acquisition and disposal have not been previously explored in the Brazilian SEP context. Reuse of needles and syringes is well known as a risk factor for several blood-borne diseases. Unsafe disposal, although representing a rather small risk to the general community, may be relevant in small drug users networks where discarded needles can be reused in a short interval of time. In addition, optimal syringe disposal conveys a successful message to communities and may be used as a marker for successful SEP intervention practices.

This study aims to describe syringe acquisition and disposal practices of clients from six different Brazilian SEPs. Sources of syringe acquisition are compared between time of injection debut and during the 6 months prior to interview.

\section{Methods}

The AjUDE-Brasil II Project was a cross-sectional multi-centre study carried out during 2000-2001 to assess the profile of IDUs attending SEPs. Its components included collection of sociodemographic, behavioural and seroepidemiologic data, a study of the morbidity and mortality of SEP clientele, programme coverage estimation using capture-recapture techniques, and a qualitative study using in-depth interviews and focus groups. Six Brazilian SEPs were chosen, aiming to broadly represent the diversity of Brazilian AIDS subepidemics and socio-economic conditions. One SEP was located in Salvador City, in Bahia State (the southernmost state of the Northeast region); one was located in São Paulo State (the richest and largest state of the Southeastern region), in a town named São José do Rio Preto. Four other SEPs were located in the Southern macro-region of the country, where the AIDS epidemic has been increasing in recent years: Porto Alegre City and Gravataí (the capital and metropolitan area of the State of Rio Grande do Sul, respectively); and Florianópolis City and Itajaí (the capital and a main port city of the State of Santa Catarina, respectively).

Participants were recruited via outreach from non-institutional venues, like streets, bars and places, where drugs were sold. Outreach workers and interviewers functioned as a mobile team, contacting, interviewing and collecting blood from drug users. IDUs aged 18 years and older who reported injecting in the last 5 years, with visible stigmata of injection drug use (i.e. needle track marks) were invited to participate. After participants provided written informed consent, face-to-face interviews were conducted. Sociodemographic characteristics, drug use, sexual practices, HIV testing and health service utilisation, and syringe utilisation and disposal practices were recorded. Blood collected from finger pricks on filter paper was tested for HIV antibodies and other blood-borne infections (Hepatitis B and C, HTLVI/II, syphilis) by ELISA, in a reference laboratory. A study of quality assurance and control, described elsewhere, was performed in order to standardise the ELISA using eluted blood from paper filter spots vis-à-vis regular ELISA using venous blood (Caiaffa, 2001; Caiaffa, Proietti, Deslandes, et al., 2002; Caiaffa, Mingoti, Proietti, 2003). Informed consent was obtained from all individuals and the protocols were approved by the Institutional Review Board of Federal University of Minas Gerais (ETIC number 168/99, on 1 March 1999).

We report upon demographic data and data on syringe and needle acquisition at the time of injection debut and during 
the 6 months prior to interview, and syringe and needle disposal during the 6 months prior to interview $(N=857)$. Proportions were compared using the chi-square distribution at a significance of $P<0.05$.

\section{Results}

A total of 857 IDUs, mostly recruited on the streets or in their neighbourhoods, were interviewed: 146 were females (17.1\%) and 709 males (82.9\%). The average age of participants was 28.5 years, $53 \%$ of participants were non-White, and $55 \%$ reported being single (Table 1). The mean age for debut in the self-injection of illicit drugs was $18.7( \pm 5.1$ years). At time of injection debut, $50.8 \%$ of participants received drugs through a friend and close friend, $26.4 \%$ from a drug dealer, $4.7 \%$ from a sexual partner and $18.1 \%$ obtained drugs by other means. Cocaine was the drug of choice for the vast majority $(74.8 \%)$.

A summary of sources of sterile syringes at the time of debut and 6 months prior to the interview is shown in Table 2 . At the time of injection debut, pharmacies $(52.6 \%)$ were the most common source of syringes reported, followed by friends or relatives (29.4\%), sexual partners (3.5\%) and drug dealers (1.4\%). SEPs were the least common source cited, with less than $1 \%$ of participants reporting receiving syringes through SEPs. Sources of sterile syringes at the time of injection debut contrast dramatically with sources of sterile syringes reported in the 6 months prior to interview.

In the 6 months prior to interview, SEPs were the most frequently reported source of clean syringes $(69.2 \%)$, followed by pharmacies $(58.3 \%)$, relatives and friends $(34.9 \%)$, sex-

Table 1

Gender, age, race and marital status distribution among injection drug users (IDUs) attending SEPs in six Brazilian cities, Brazil, 2000-2001

\begin{tabular}{lrr}
\hline Characteristics & $N$ & $\%$ \\
\hline Gender $^{\mathrm{a}}$ & & \\
$\quad$ Female & 146 & 17.1 \\
Male & 709 & 82.9 \\
$\quad$ Age range (years) & \\
$<20$ & & \\
$20-30$ & 99 & 11.6 \\
$31-40$ & 460 & 53.8 \\
$41-50$ & 208 & 24.3 \\
51 and more & 82 & 9.6 \\
Race & 6 & 0.7 \\
White & & \\
Non-White & 400 & 46.8 \\
Marital status & & 53.2 \\
Single & 454 & \\
Married & & 54.7 \\
Divorced & 468 & 9.0 \\
Widow & 288 & 2.6 \\
\hline
\end{tabular}

${ }^{a}$ Missing information was excluded.
Table 2

Sources of injection equipment (syringes and needles) at first injection and in the last 6 months among injection drug users (IDUs) attending SEPs in six Brazilian cities, with respective proportions and rank posts, Brazil, 2000-2001

\begin{tabular}{|c|c|c|c|c|c|c|}
\hline \multirow[t]{2}{*}{ Sources $^{\mathrm{a}}$} & \multicolumn{3}{|c|}{ First injection } & \multicolumn{3}{|c|}{ Last 6 months } \\
\hline & $N$ & $\%$ & Rank & $N$ & $\%$ & Rank \\
\hline Pharmacies & 450 & 52.6 & 1 & 378 & $58.3^{*}$ & 2 \\
\hline Sexual partner ${ }^{b}$ & 30 & 3.5 & 4 & 67 & $16.4^{* *}$ & 4 \\
\hline Relatives/friends & 251 & 29.4 & 2 & 324 & $34.9^{*}$ & 3 \\
\hline SEP & 8 & 0.9 & 6 & 451 & $69.2^{* *}$ & 1 \\
\hline Drug dealers & 12 & 1.4 & 5 & - & - & \\
\hline Other $^{c}$ & 86 & 10.0 & 3 & 33 & $5.9^{*}$ & 5 \\
\hline
\end{tabular}

${ }^{\text {a }}$ Multiple answers allowed.

${ }^{\mathrm{b}}$ Regular or occasional.

${ }^{\mathrm{c}}$ Includes: garbage, sewage and toilets.

* Proportions significantly different at the level of $P=0.05$.

** Proportions significantly different at the level of $P=0.01$.

ual partners (16.4\%) and, finally, by miscellaneous sources (5.9\%). Drug dealers were no longer ranked.

Sources of syringe acquisition in the past 6 months varied by SEP (Table 3): Over half (54-86\%) reported obtaining their syringes from outreach workers; $40-69 \%$ through pharmacies; and 3-27\% from casual and close friends. Additional sources, such as hospitals and other health services, were reported by $3-27 \%$ of SEP clients. About $84 \%$ of participants reported injecting only with sterile syringes in the past 6 months; $3.7 \%$ of participants reported injecting only with used syringes, and $12.0 \%$ of participants sometimes injected with new and sometimes with used syringes.

At the time of injection debut, 42.1 and $19.5 \%$ of participants reported being helped to inject by close and casual friends, respectively, whereas $26 \%$ of participants reported having injected without the help of others. Sexual partners and relatives facilitated the first injection for 5\% of participants, and drug dealers facilitated the first injection for less than $2 \%$.

Syringe disposal preferences in the past 6 months were recorded as an open question, allowing up to two responses per interviewee. A total of 970 disposal responses were recorded. Almost one third of these reports $(28.5 \%)$ reported disposal in community biohazard-protected disposal boxes made available by SEPs. Sixty percent of responses reported disposal on the streets, in public squares, or in the garbage or sewage. Nearly $7 \%$ of responses reported 'saving' used tools, hiding them in trees or wood or saving them inside a plastic bottle, and $4.7 \%$ of responses cited other disposal alternatives, such as burying or burning.

Participants were classified as 'safer' or 'unsafe' based on two reported responses of safe disposal options. For example, disposal in a box made available by SEPs was classified as using 'safer' disposal practices; those reporting one or two unsafe disposal practices were classified as 'unsafe'. Only 5.9\% IDUs reported consistently safer syringe disposal; $61.7 \%$ reported to have only used unsafe disposals, and $32.3 \%$ reported combinations of safer and unsafe dis- 
Table 3

Syringe and needle acquisition in the last 6 months among injection drug users (IDUs) attending SEPs in six Brazilian cities, with respective proportions, Brazil, 2000-2001

\begin{tabular}{|c|c|c|c|c|c|c|c|c|c|c|c|c|c|}
\hline & \multicolumn{2}{|c|}{ Porto Alegre } & \multicolumn{2}{|c|}{ São José do Rio Preto } & \multicolumn{2}{|c|}{ Itajaí } & \multicolumn{2}{|c|}{ Florianópolis } & \multicolumn{2}{|c|}{ Salvador } & \multicolumn{2}{|c|}{ Gravataí } & \multirow[t]{2}{*}{$P$ value $^{\mathrm{a}}$} \\
\hline & $N$ & $\%$ & $N$ & $\%$ & $N$ & $\%$ & $N$ & $\%$ & $N$ & $\%$ & $N$ & $\%$ & \\
\hline Outreach & 154 & 68.4 & 84 & 86.6 & 19 & 54.3 & 36 & 69.2 & 107 & 68.2 & 51 & 59.3 & $<0.01$ \\
\hline Pharmacies & 126 & 57.3 & 39 & 40.2 & 23 & 65.7 & 29 & 56.9 & 101 & 63.9 & 60 & 69.0 & $<0.01$ \\
\hline Close friend & 67 & 31.2 & 22 & 22.9 & 12 & 36.4 & 22 & 40.0 & 18 & 12.3 & 23 & 26.4 & $<0.01$ \\
\hline Casual friend & 72 & 33.3 & 24 & 24.7 & 11 & 33.3 & 20 & 37.0 & 14 & 9.7 & 19 & 21.8 & $<0.01$ \\
\hline Regular sex partner & 19 & 12.4 & 3 & 5.2 & 5 & 27.8 & 6 & 22.2 & 5 & 5.0 & 3 & 3.2 & $<0.01$ \\
\hline Eventual sex partner & 11 & 9.6 & 2 & 5.6 & 3 & 11.5 & 6 & 20.7 & 3 & 2.9 & 2 & 4.2 & 0.02 \\
\hline Unknown person & 24 & 11.3 & 2 & 2.1 & 4 & 12.1 & 5 & 9.8 & 3 & 5.6 & 8 & 5.7 & 0.06 \\
\hline Hospitals & 53 & 24.7 & 22 & 22.9 & 6 & 17.6 & 14 & 26.9 & 10 & 6.9 & 3 & 3.4 & $<0.01$ \\
\hline
\end{tabular}

${ }^{\text {a }} P$ values result of the comparison between proportions across SEPs.

posal. Overall, the vast majority (94\%) of the interviewees reported unsafe practices.

Disposal practices varied across SEP (Fig. 1). Higher proportions of IDUs in Porto Alegre (38.2\%) and Gravataí (33.9\%) used the safer syringe disposal boxes available by SEPs, as compared to IDU practices in Itajaí (9.3\%), São José do Rio Preto (15.7\%) and Florianópolis (18.2\%). Disposal on the streets was reported more often in Florianópolis (39.8\%), São José do Rio Preto $(32.1 \%)$ and Itajaí (29.6\%) than in Porto Alegre (12.8\%). Disposal in the garbage, sewage or toilets was reported by more than $30 \%$ of participants in all locations, and by about $45 \%$ of participants in the two coastal cities of Itajaí and Salvador.

\section{Discussion}

This study of urban, mainly poor and street-recruited IDU demonstrates that IDUs in Brazil continue to use a variety of sources for syringe acquisition and maintain hazardous syringe disposal practices, even in the context of preventive strategies implemented by SEPs. The significance of SEP as a source of needles/syringes increased dramatically between time of injection debut and the 6 months prior to the interview. Virtually irrelevant at the time of initiation of injection, SEPs subsequently represented the most important source of syringe provision by the end of the study period. Further studies should evaluate the interplay of individual and ecological level fac-

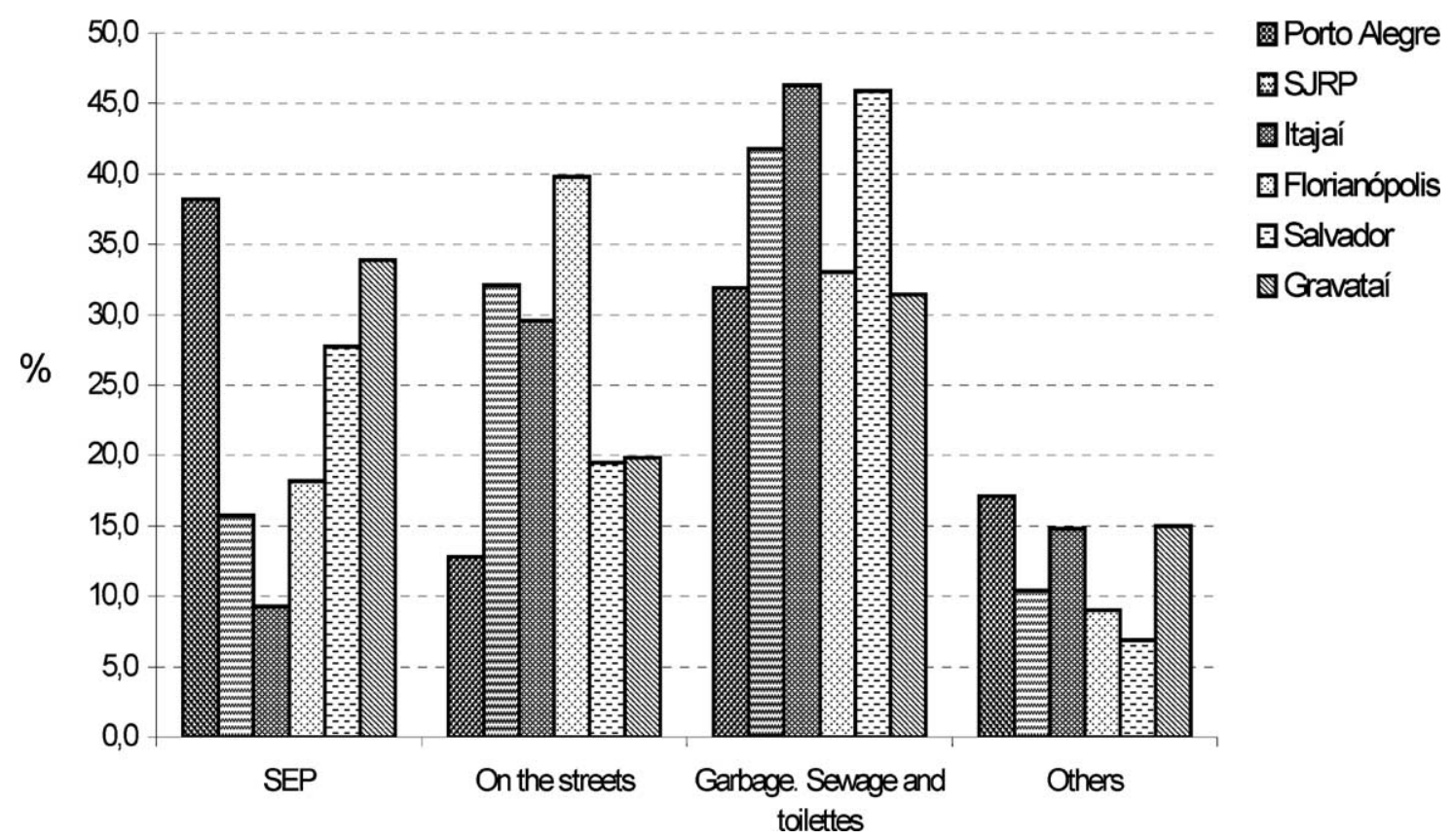

Fig. 1. Disposal practices in the last 6 months among injection drug users (IDUs) attending SEPs in six Brazilian cities, with respective proportions and rank posts (in superscript), Brazil, 2000-2001. All comparisons between proportions among SEPs were significantly different at the level of $P=0.01$. The interviewee was allowed to give two indications: 'SEP disposal' meant delivered to outreach worker and/or in disposal boxes; 'on the streets' meant on the streets, parks, avenues, open field; 'others' included burn, dig in the ground, save on trees, woods or plastic bottles. 
tors in determining individual behavioural change among IDUs.

Pharmacies were the most commonly reported source of syringes of at the time of injection debut, and were the second most commonly cited source in 6 months prior to the interview. These results are comparable to a study in the United States, despite different laws and norms related to syringe acquisition (Gleghorn et al., 1998).

It would be expected that offering a new source for sterile syringe acquisition at no cost, in the form of SEPs, might result in a profound shift in the frequency of syringe purchases from pharmacies. However, in this study, this hypothesis was not supported by these data. Syringe acquisition behaviours are influenced by an interplay of several psychological and contextual factors (Jungle, Bouey, Cohn, et al., unpublished manuscript), including contextual factors prior to injection, characteristics of the drug scene and strategies employed to finance drug habits, and local legislation and law enforcement practices (Deslandes, Mendonça, Caiaffa, \& Doneda, 2002). The cross-sectional nature of the present study precludes further analysis of the putative influence of local drug scene dynamics on acquisition and disposal practices.

This study demonstrates that pharmacies remain an important source of clean/sterile syringes, even in settings with minimum barriers to SEP use. Pharmacies thus have the potential to contribute and augment current efforts to prevent HIV infection in IDUs and their sexual partners. However, inappropriate pharmacist attitudes and practices can stigmatise the clientele and discourage acquisition (Gleghorn et al., 1998). In a study in the USA, $12 \%$ of pharmacists refused to sell syringes to African-Americans and $18 \%$ reported an insufficient supply of syringes for sale (Lurie et al., 1998). On the other hand, motivated pharmacists conscious of their role as health professionals play a key role in the effort to curb transmission of HIV and other blood-borne pathogens (Sheridan et al., 2000).

In conjunction with providing sterile needles, either through distribution or exchange, SEPs have established comprehensive and original strategies to address needle/syringe disposal, such as community drop-off boxes, systematic collection in the field, containers for biohazard disposal at community sites, and collection points in hospitals and pharmacies (Macalino et al., 1998). The argument that SEPs would augment the number of used syringes discarded in the community has been refuted (Doherty, Jungle, Rathouz, et al., 2000). Qualitative studies have further demonstrated that the number of discarded needles on the streets may decrease after the introduction of community syringe disposal programmes (Keyl, Gruskin, Casano, et al., 1998). Also, comparing SEP clients with non-clients, previous research by our group has shown that inadequate disposal practices in the last month prior to the interviewvery high in both groups-were significantly lower among clients $(75 \%)$ than non-clients (100\%) (Caiaffa et al., 2002).

However, syringe disposal issues remain a challenge in Brazil and world-wide. Besides the strong negative re- sponses from some communities, disposal is a concern for IDUs themselves. Criminal penalties for the possession of syringes are a substantial deterrent to full engagement in community efforts to safely dispose of used syringes. IDUs frequently report fear of harassment or arrest for syringe possession laws, even in regions (e.g. some U.S. states) with decriminalising laws. Also, IDUs frequently do not want to be identified as 'drug users' by depositing a used needle in an appropriate disposal container (Riley, Beilenson, Vlahov, et al., 1998). Brazilian law is unclear respecting the legality of possession of syringes and other drug injecting paraphernalia, but there are anecdotal reports of police using the possession of drug injecting paraphernalia as additional proof of illicit consumption in anti-drug raids and legal processes.

The findings from the present study emphasise that a concerted effort to improve the safety of syringe acquisition and disposal practices, involving SEPs, pharmacies and other satellite programmes is needed. SEPs, pharmacy-based distribution/exchange initiatives and other satellite syringe distribution alternatives should function as complementary resources in the effort to increase service coverage (Lurie et al., 1998). Pharmacy and other 24-h health care sites must be accompanied by educational programmes to teach health workers, including pharmacists, about the proper use of syringes, and how to handle any used syringes returned to them. The development of practical plans for safe disposal of syringes by IDUs should be included in this integrated effort.

Although more expensive than other options, SEPs are better equipped to provide ancillary services, such as HIV testing and counselling, referrals to health and drug treatment, condom distribution and health education. Such integrated interventions may help to minimise syringe disposal problems and gain community support (Bastos \& Strathdee, 2000; Lurie et al., 1998). Some SEPs have carried out additional field activities, such as the systematic collection of disposal containers and used drug paraphernalia, treated as biohazard waste, and the distribution of yellow biohazard drop boxes/containers at strategic points in communities (Macalino et al., 1998). Some of these initiatives have been successfully implemented in the Brazilian context (Bastos, 2000).

The present study has some methodological limitations. Socially desirable answers could have occurred concerning behaviours known to be risky, such as harmful syringe acquisition and disposal practices. Another limitation of the analysis is associated with the data collection procedures, due to the fact that acquisition and disposal practices were basically assessed by broad sets of items and not specific scales.

Despite study limitations, some recommendations can be made. Contextual restrictions and the absence of a comprehensive public health education policy may be functioning as barriers to the recommendation of one-time use of sterile syringes for IDU who cannot stop injecting. Increased access to legal, inexpensive and timely sterile syringes, 
and comprehensive educational initiatives on the merits of one-time use and safe disposal must be reinforced in the SEP context and expanded to other health care sectors, especially pharmacies and other satellite exchange facilities.

Given the geographic and temporal heterogeneity of the Brazilian HIV/AIDS epidemic, where mature regional epidemics overlap with extensive and fast spreading subepidemics, integrated prevention programmes performed by different health sectors are a key strategy to effectively reduce transmission. Attempts should be made to minimise prejudices surrounding syringe purchase and possession. A concerted effort to increase supply of clean syringes and to improve safe disposal is called for.

Additional research in the Brazilian context is needed in order to implement culturally sensitive interventions, tailored to Brazilian social, cultural and contextual characteristics. The present study should be viewed as a first step toward a better understanding of local practices surrounding syringe acquisition and disposal.

\section{Acknowledgements}

This work was carried out by the Federal University of Minas Gerais, with technical and financial support of the Cooperation Project AD/BRA/99/EO2 between the National Program of STD/Aids and the U.N. Office on Drugs and Crime (UNODC). Drs. Caiaffa, Bastos and Proietti are recipients of Brazilian Research Council (CNPq) scholarships. Thanks are due to Maya Petersen, UC Berkeley, for her help in the process of revision. The AjUDE-Brasil II Project team includes: Waleska Teixeira Caiaffa (PI), Anna Bárbara Carneiro Proietti, Eduardo Alves Mendonça, Fernando Augusto Proietti, Francisco Inácio Bastos, Nélio Januário, Sueli Aparecida Mingoti, Suely Deslandes, Denise Doneda, Denise Gandolfi, Aline Cristine Souza Lopes, Divane Leite Matos, Marta Aparecida Barbosa Chagas, Mônica Malta, Rodrigo Carazolli da Silva, Ronald Elsin Moraes Eller, Angela Cristina Maia, Isabela Furtado de Mendonça Picinim, Henrique Fernades Mendes, Mariana Hacker, Renata Cristina Rolim Marinho and Rosana Teixeira Caiaffa. SEP Florianópolis (SC): Ioná Maria Cardoso and team; SEP Gravataí (RS): Rosa Maria Bittencourt Mayer and team; SEP Itajaí (SC): Rosalie Knoll and team; SEP Porto Alegre (RS): Mirtha Delia Sendic Sudbrack and team; SEP Salvador: Tarcísio Andrade and team; SEP São José do Rio Preto (SP): Elza Maria Alves Ferreira and team.

\section{References}

Bastos, F. I. (2000). Drugs and AIDS: A case study from Brazil. Urban Health Development Bulletin, 3, 30-38.

Bastos, F. I., \& Strathdee, S. A. (2000). Evaluating effectiveness of syringe exchange programmes: Current issues and future prospects. Social Science \& Medicine, 51, 1771-1782.
Brazil. (2002). Boletim Epidemiológico de AIDS XV; no. 01: $48^{a} / 2001$ à $13^{a} / 2002$ semanas epidemiológicas, October-March 2002. Brasília: Ministry of Health.

Caiaffa, W. T. (2001). Projeto AjUDE-Brasil. Avaliação epidemiológica dos usuários de drogas injetáveis dos projetos de redução de danos apoiados pela CNDST e Aids (Brasília, CNDST e Aids/Ministério da Saúde, Série Avaliação no. 6, 324 pp.). Brasília: Ministério da Saúde. Available: www.aids.gov.br

Caiaffa, W. T., Proietti, F. A., Deslandes, S., Mingoti, S. A., Marques, L. F., Mendonça, E. A. (2002). Harm reduction as a campaign: A public health concern-A quantitative and qualitative approach in the Brazilian Syringe Exchange Program (SEP)—The AjUDE-Brasil Project (Vol. 1, p. 63). 12th International Conference on the Reduction of Drug-related Harm, April 1-5, 2001, New Delhi.

Caiaffa, W. T., Proietti, F. A., Mingoti, S. A., Carneiro-Proietti, A. B., Doneda, D., \& Gandolfi, D. et al. (2002). The dynamics of HIV among IDU in Brazil: Empirical and theoretical considerations. Brazilian Journal of Epidemiology, V(Suppl. 1), 302.

Caiaffa, W. T., Mingoti, S. A., Proietti, F. A., Carneiro-Proietti, A. B., Silva, R. C., Lopes, A. C. S., et al. (2003). Estimation of the number of Injecting drug users (IDUs) attending an outreach Syringe Exchange Program (SEP), and the infection with Human Immunodeficiency Virus (HIV) and Hepatitis C virus (HCV). Journal of Urban Health.

Chitwood, D., Clyde, B., Inciardi, J. A., McBride, D. C., Comerford, M., \& Trapido, E. et al. (1990). HIV seropositivity of syringes from shooting galleries in South Florida. American Journal of Public Health, 80, 150-152.

Deslandes, S. F., Mendonça, E. A., Caiaffa, W. T., \& Doneda, D. (2002). As Concepções de Risco e de Prevenção Segundo a ótica dos Usuários de Drogas Injetáveis. Cad. Saude Pub., 18, 141-151.

Diaz, T., Chu, S., Weinstein, B., Mokotoff, E., \& Jones, T. S. (1998) injection and syringe sharing among HIV-infected injection drug users: Implications for prevention of HIV transmission. Journal of Acquired Immune Deficiency Syndromes and Human Retrovirology, 18(Suppl. 1), S76-S81.

Doherty, M. C., Jungle, B., Rathouz, P., Garfein, R. S., Riley, E., \& Vlahov, D. (2000). The effect of a needle exchange program on numbers of discarded needles: A 2-year follow-up. American Journal of Public Health, 90, 936-939.

Gleghorn, A. A., Gee, G., \& Vlahov, D. (1998). Pharmacists' attitudes about pharmacy sale of needles/syringes and needle exchange programs in a city without needle/syringe prescription laws. Journal of Acquired Immune Deficiency Syndromes and Human Retrovirology, 18(Suppl. 1), S89-S93.

Groseclove, S. L., Weinstein, B., Jones, T. S., Valleroy, L. A., Fehrs, L. J., \& Kassler, W. J. (1995). Impact of increased legal access to needles and syringes on practices on injecting-drug users and police officers-Connecticut, 1992-1993. Journal of Acquired Immune Deficiency Syndromes and Human Retrovirology, 10, 82-89.

Heimer, R., Khoshmood, K., Bigg, D., Guydish, J., \& Junge, B. (1998) Syringe use and reuse: Effects of syringe exchange programs in four cities. Journal of Acquired Immune Deficiency Syndromes and Human Retrovirology, 18(Suppl. 1), S37-S44.

Jungle, B., Bouey, P., Cohn, S., Perceptions and practices surrounding syringe acquisition by participants in the Baltimore syringe exchange program. Unpublished manuscript.

Keyl, P. M., Gruskin, L., Casano, K., Montag, H., Junge, B., \& Vlahov, D. (1998). Community support for needle exchange programs and pharmacy sale of syringes: A household survey in Baltimore, Maryland. Journal of Acquired Immune Deficiency Syndromes and Human Retrovirology, 18(Suppl. 1), S82-S89.

Lurie, P., Gorsky, R., Jones, T. S., \& Shomhe, L. (1998). An economic analysis of needle exchange programs and pharmacy-based programs to increase sterile syringe availability for injection drug users. Journal of Acquired Immune Deficiency Syndromes and Human Retrovirology, 18(Suppl. 1), S126-S132. 
Macalino, G. E., Springer, K. W., Rahman, Z. S., Vlahov, D., \& Jones, T. S. (1998). Community-based programs for safe disposal of used needles and syringes. Journal of Acquired Immune Deficiency Syndromes and Human Retrovirology, 18(Suppl. 1), S111S119.

Montella, F., Di Sora, F., \& Recchia, O. (1992). Can HIV infection be transmitted by a "discarded" syringe? Journal of Acquired Immune Deficiency Syndromes, 5, 1274-1275.
Riley, E., Beilenson, P., Vlahov, D., Smith, L., Koenig, M., \& Jones, T. S. et al. (1998). Operation red box: A pilot project of needle and syringe drop boxes for injection drug users is East Baltimore. Journal of Acquired Immune Deficiency Syndromes and Human Retrovirology, 18(Suppl. 1), S120-S125.

Sheridan, J., Lovell, S., Turnbull, P., Parsons, J., Stimson, G., \& Strang, J. (2000). Pharmacy-based needle exchange (PBNX) schemes in Southeast England: A survey of service providers. Addiction, 95, 1551-1560. 